\title{
The effect of macrophytic cover on survival of Palaemonetes pugio and $P$. vulgaris (grass shrimp) in the presence of predatory Fundulus heteroclitus (killifish)
}

\author{
Henry C. Merchant ${ }^{1,2}$, Ritindra N. Khan ${ }^{3}$ \& Robert E. Knowlton ${ }^{2}$ \\ 'corresponding author: hmerchnt@gwu.edu; ${ }^{2}$ Department of Biological Sciences, The George Washington \\ University, Washington, D.C. 20052, U.S.A.; ${ }^{3}$ Department of Biology, Armstrong Atlantic State University, \\ 11935 Abercorn St., Savannah, GA. 31419, U.S.A.
}

Key words: Palaemonetes, predation, macrophytic cover, survivorship

\begin{abstract}
Effects of three different macrophytic covers and the presence of alternative prey on survival of grass shrimp (Palaemonetes pugio and $P$, vulgaris) subjected to predation by killifish (Fundulus heteroclitus) were studied in the laboratory. Overall, survival of $P$, vulgaris was significantly greater $(82 \%)$ than that of $P$. pugio $(70 \%)$. This difference in survival was attributed to the greater tendency of $\boldsymbol{P}$. pugio to swim outside the covers, making it more vulnerable to predation. Both prey species responded similarly to the different cover conditions. Survival without cover (gravel substrate) was $48 \%$. In cover provided by a plastic plant made to resemble Ambulia, $75 \%$ of the starting population survived. In cover furnished by field-collected specimens of the flat chlorophyte, Ulva, survival was $71 \%$, compared to $98 \%$ survival in the branched green alga, Codium. Predation pressure on neither species was significantly enhanced or diminished by the presence of a second prey species.

For both grass shrimp species, increased survival in Codium in the presence of the predator was attributed to the physically more complex nature of this macrophytic cover.
\end{abstract}

\section{Contents}

\begin{tabular}{ll} 
Abstract & 61 \\
Introduction & 61 \\
Materials and methods & 62 \\
\multicolumn{1}{c}{ Field methods } & 62 \\
$\quad$ Laboratory methods & 62 \\
$\quad$ Analytical and statistical methods & 64 \\
Results & 65 \\
$\quad$ Behavior of prey and predator & 65 \\
Macrophytic cover, predation, and survivorship & 65 \\
Discussion & 67 \\
Acknowledgements & 70 \\
References & 70 \\
Appendix & 71
\end{tabular}

\section{Introduction}

Vast numbers of grass shrimp (Palaemonetes spp.) occur in shallow water of estuaries and bays of the U.S. Atlantic and Gulf coasts (Anderson, 1985), where they congregate on areas of bare mud, sand and shell flats, and on wooden pilings (Knowlton et al., 1994), but they are particularly abundant in dense stands of underwater macrophytes (Orth et al., 1984). The two most common species of Palaemonetes associated with tidal marshes and creeks of the mid-Atlantic region are $P$. pugio and $P$. vulgaris (Williams, 1984). Because these two species are especially common in areas with macrophytic cover, the nature of the vegetation may be presumed to have a major influence on their abundance, distribution, and loss to predation. Indeed, distributional differences in relation to structural characteristics of macrophytic algae have been demonstrated in a laboratory setting (Khan et al., 1997).

Predation has been shown to influence the distribution and abundance of species within marine habitats (Kneib, 1988; Primavera, 1997). When predators are present, prey organisms frequently switch microhabitats, choosing a site where they are less vulnerable (Main, 1987; Everett and Ruiz, 1993). Both laboratory and field experiments have indicated that for many species of invertebrates, including Palaemonetes spp., macrophytic vegetation can provide protection from predators (Rozas and Odum, 1988; Tayasu et al., 1996). With the decline of submerged aquatic vegetation in deeper waters of Chesapeake Bay, many animals have been 
reported to shift from deeper water $(>1$ meter) to shallower conditions $(<35 \mathrm{~cm})$ along the shoreline where important structural features created by woody debris provide refuge from predation (Ruiz et al., 1993).

Interactions between prey species, especially as they influence the use of cover, may alter the impact of a predator upon those prey species. For example, Thorp (1976) felt that oyster shell provides protection from predation and that $P \times$ vulgaris is more resistant to predation because it displaces $P$. pugio from a shelly substrate.

The killifish Fundulus heteroclitus is a permanent marsh resident and is abundant in areas inhabited by Palaemonetes. Studies of stomach contents have indicated that grass shrimp are an important component of the killifish diet (Heck and Thomas, 1981; Overstreet and Heard, 1982).

The role of macrophytic covers in predation served as the focus of the present study whose primary purpose was to determine how the presence of $F$. heteroclitus quantitatively affects survival of $P$. pugio and $P$. vulgaris in the various experimental covers. The questions asked were: 1) Is predation pressure the same for both species of grass shrimp? 2) Does macrophytic cover reduce the amount of predatory loss for one or the other prey species of grass shrimp? 3) If macrophytic cover reduces loss to predators, are all kinds of macrophytic cover equally effective in reducing the loss? 4) Does the presence of the second prey species of grass shrimp enhance or lessen the predatory loss of the first prey species?

\section{Materials and methods}

\section{Field methods}

Animals and natural cover types used in all experiments were collected from Indian River Bay, a small Atlantic estuary in southeast Delaware, U.S.A. This site was chosen because the sympatric grass shrimp species $P$. pugio and $P$. vulgaris, the killifish Fundulus heteroclitus, and natural plant covers (the green algae Codium fragile and Ulva lactuca) were easily found there. A dip net was used to collect both grass shrimp species. Killifish and submerged macrophytes were collected with a seine drawn over relatively flat areas of tidal creeks. Substrate items were removed from the top $2 \mathrm{~cm}$ of marsh surface with a shovel at low tide. At the time of collection, Ulva and Codium dominated benthic macrophytes within the sampling area, and both were collected by hand. All field collected animals, plants, and substrate materials were transported to the laboratory in separate plastic containers.

\section{Laboratory methods}

In the laboratory, macrophytes and substrates were placed in separate 20-1 plastic buckets containing aerated seawater. Shrimp were sorted by species and placed into separate 350-1 flow-through aquaria equipped with undergravel biological filters. Aeration was provided by air stones that were connected via plastic tubing to a constant air supply. In these stock holding tanks, salinity ( $35 \mathrm{ppt}$ ), temperature $\left(22^{\circ} \mathrm{C}\right), \mathrm{pH}(8.2)$, dissolved oxygen $(18 \mathrm{mg} / \mathrm{l})$, and photoperiod (12L:12D) were held constant. Photoperiod was maintained via automatic timers. In an attempt to minimize the influence of possible conditioning during holding, both species of shrimp were held without any cover or vertical structure (including macrophytes) over a level layer of colorless, commercially obtained aquarium gravel composed of quartz fragments. The gravel fragments were not homogeneous in size. The largest particles were $0.95 \mathrm{~cm}$ in diameter and were retained on a \#5 USA Standard Testing Sieve; the smallest were retained on a \#21 sieve. One percent (by weight) of the gravel was retained on the \#5 sieve; $72 \%$ on a \#10 sieve; $18 \%$ on a \#12 sieve; $9 \%$ on the \#21 sieve. While awaiting use in experiments, shrimp were fed daily surfeit amounts of commercially obtained fish food (Tetra-Min ${ }^{\circledast}$, manufactured by TetraWerke, Melle, Germany). Food was not offered during the 12-hour period immediately preceding selection of shrimp for use in the experiments.

In a separate holding aquarium, Fundulus heteroclitus ( $80 \pm 5 \mathrm{~mm}$ in length) were maintained over bare gravel in the same physico-chemical conditions as the grass shrimp. Killifish were fed a diet of Palaemonetes daily except that no prey were pro- 
vided for 48 hours prior to their use as predators in experiments.

All experiments took place in four separate aquaria arranged linearly on a bench within the same room and at the same temperature and photoperiod as the holding tanks. Preliminary experiments indicated that there were no position effects associated with the location of the tanks with respect to each other. The experimental aquaria were each $60 \times 30 \times 35 \mathrm{~cm}$ (approx. 63-1) and were half filled with artificial sea water (35 ppt; $\mathrm{pH} 8.2$ ) prepared by dissolving Instant Ocean ${ }^{\oplus}$ sea salts in deionized water. There was no flow-through system in the experimental aquaria. Air stones connected to the same air supply as the holding tanks provided constant aeration except that in an attempt to remove a possibly confounding source of procedural variation, the stones were removed 12 hours prior to and during the experiments. Earlier experiments (Khan et al., 1995) established species differences in the number of grass shrimp resting on the commonly occurring natural substrates (wood, sand, shell, and mud). Since the use of macrophytic cover in response to the presence of the predator might be influenced by an association with a particular type of natural substrate, the same artificial (and therefore more likely to be neutral) substrate used in the holding tanks (colorless quartz aquarium gravel) was used in the present experiments. Four plastic trays (each $30 \times 15 \mathrm{~cm}$ ) were tightly fitted into the bottom of each aquarium; into each tray a level (2-cm thick) layer of aquarium gravel was placed. In one of the aquaria, all four trays were left without macrophytic cover. In the other three aquaria, individuals of one type of macrophytic cover were randomly selected from the stock tanks and added to all four trays. One of the three aquaria received Codium; another, Ulva; the third, a synthetic "plant" made of a plastic material (polypropylene) superficially resembling Ambulia. Withìn each aquarium enriched with maorophytes, approximately $90 \%$ of the area was covered by individuals of the appropriate macrophyte. Ten gram lead weights held the macrophytes in position. Highly branched Codium offered cover that was a moreor-less erect loose tangle of semi-rigid thalli at various levels above the substrate. The individuals of Codium were densely covered with periphyton.
The broad, flat thalli of Ulva "flopped" over, providing a broad sheet of cover appressed at the unanchored edge against the gravel substrate. Periphyton on Ulva, if present, was not noticeable. The synthetic "Ambulia" provided structure characterized by stiff upright "stems" with regular broader "leaves" at regular vertical intervals. No periphyton was present on the "Ambulia."

In all of the experiments reported here, counts of shrimp were made during daylight hours under ambient room.lighting. Shrimp tended to be sedentary for sufficiently long times to allow careful counting. When macrophytic covers were provided, their nature and density did not interfere with accurate counting of shrimp. Codium was openly branched and the loose tangle of thalli permitted seeing into the cover. Erect portions of Ulva provided passages between the thalli that allowed the observer to readily see into the cover, and although Ulva tended to flop over on itself, it did so such that shrimp could congregate within the spaces between the bends and folds. Shrimp tended not to push themselves between the appressed edge of the Ulva thalli and the substrate, and therefore remained visible to the experimenter. "Ambulia" was upright and rigid with many spaces between "stems" and "leaves" that permitted seeing into the cover.

After the experimental aquaria were established, 20 individual Palaemonetes pugio $(30 \pm 5 \mathrm{~mm}$ in length) and two Fundulus heteroclitus $(80 \pm 5 \mathrm{~mm}$ in length) were selected at random from the stock aquaria and added to each. of the experimental aquaria. Numbers of prey and predator individuals used per replicate experiment were based upon pilot studies conducted over bare gravel (as used in the present study) which indicated that one killifish of this size could consume five Palaemonetes of either species in 24 hours. If this exploitation rate prevailed in the present study, a starting population of 20 prey individuals would leave 10 live individuals after 24 hours exposure to the predator. The aquaria were left undisturbed for 24 hours after which the Fundulus were removed from the aquaria, and the number of surviving prey was counted and recorded. Counts are known to be accurate because at the time of counting, all shrimp were removed, recounted, and discarded. Killifish, live and plastic 
plants, and gravel also were removed from the aquaria and discarded. This entire experimental procedure was repeated once using different individuals of the same prey species, different individuals of the predator (Fundulus), different individuals of live and plastic macrophytic cover, and different gravel. These procedures were repeated twice more using the second prey species, Palaemonetes vulgaris ( $30 \pm 5 \mathrm{~mm}$ in length), instead of $P$. pugio.

The experimental protocol was repeated two more tîmes, but in each of these replicates, 15 individuals of each prey species were substituted for the 20 individuals of a single prey species. In these "mixed-species" experiments, distinguishing the two species was made easier by prior staining of one of the species with Alcian blue. It has been established that this procedure affects neither the viability nor the behavior of stained individuals (Coen et al., 1981). In the first of these mixed species replicates, $P$. vulgaris was stained; in the second, $P$. pugio. In the present studies, the similarity in the number of each species consumed by the predator when the prey was stained vs. unstained suggests that vulnerability to predation was also not affected by staining.

\section{Analytical and statistical methods}

Pilot studies indicated that after an initial acclimation period spent in the holding tanks, and in the absence of a predator, no shrimp died during exposure to the conditions of the experiments. Therefore, the distribution of the mean number of shrimp surviving in each condition of macrophytic cover in the presence of the predator was compared (using a Chi-square test) to the expected distribution based upon the a priori assumption that no deaths (thus $100 \%$ survival) would occur in each cover condition. A significant Chi-square value was taken to indicate a significant influence of the predator upon the number of survivors in the four macrophytic cover conditions. In the Chi-square analysis, the null hypothesis was that there is no difference between the observed distribution of survivors and the distribution expected by assuming that the predator would consume no prey in any cover condition. The alternative hypothesis was that the predator would consume enough prey in at least one of the cover conditions to cause the distribution of surviving shrimp among the cover types to be significantly different from that based upon 100 percent survival in all cover conditions.

Since in this study all deaths were assumed to be due to predation, predation pressure was measured by calculating the percentage of the starting population of each prey species that was missing after 24 hours of exposure to the predator.

The number of shrimp surviving in each condition of macrophytic cover in the presence of the predator was converted to percent of the starting population of shrimp of that species. The percent values were normalized using the angular transformation (Sokal and Rohlf, 1995).

A test for homogeneity of variances between the data for each species was conducted by calculating separately the total variance within the arcsine transformed data for each species ( $P$. pugio and $P$. vulgaris). Following Sokal and Rohlf (1995), these variances were compared using an F- test and found to be not significantly different $(F=1.15 ; \mathrm{df}=15$, $15 ; .10<\mathrm{P}<.25)$. Therefore, the arcsine transformed survivorship data for both species were combined into a single data set and analyzed using a threefactor analysis of variance (ANOVA). In this analysis, the main effects were "species" (predator's effect on the survivorship of each prey species: $P$. pugio and $P$. vulgaris); "cover" (predator's effect on the prey's survivorship in each type of cover: none, Ulva, Codium, and "Ambulia"); "exposure" (predator's effect on the prey's survivorship when the prey were exposed to the predator alone or in the presence of the second prey species).

In the ANOVA, estimates of the variation contributed by the main effects (the independent sources of variation) and by the interactions between and among them were compared with random (error) variation using F-tests. The working hypothesis was that one or more of the designed sources of variation and/or interactions between and among them contributes more variation than that due to error and thereby is identified as a significant contributor to the differences in observed shrimp survivorship among the different macrophytic covers. When interactions were determined to be significant, further testing of the entangled main effects was 
precluded. Multiple-means analyses using Tukey's honestly significant difference (T-method of Sokal and Rohlf, 1995) were performed on sources of variation showing significant $F$ values $(\alpha=.05)$.

In each F-test, the null hypothesis was that there is no difference between the variance contributed by the main effect (or by the interaction between or among main effects) and the variance due to chance (error). If the null hypothesis for any source of variation was rejected, then the null hypothesis for the T-method multiple-means comparisons was that all means of all levels for the significant source of variation were not significantly different from each other.

\section{Results}

\section{Behavior of prey and predator}

Although the focus of the present work was not to describe the behavior of the participants during exposure of the prey to the predator, certain behaviors and features of the predator-prey interaction were repeatedly observed and noted in all of the experiments. These behaviors are reported here because they may provide additional insight into understanding the role of macrophytic cover in the predator-prey interaction between Fundulus and Palaemonetes.

In the absence of the predator, Palaemonetes was found within the cover and on the substrate around the cover. At any given time, a small number of animals $(<10 \%)$ swam in the water column above the cover.

Outside and within macrophytic cover, individuals of both species of Palaemonetes spent the majority of time resting (rest $=$ time spent in no overall body movement; antennae, mouth parts, and appendages may or may not be in motion during rest). Typically Palaemonetes moved from one resting place to another by a short burst of swimming activity that was accomplished by typical metachronal waving of the pleopods. This movement of the appendages lifted the individual up (from its resting place), carried it through the water, and settled it at another resting place. An approach or attack by a predator (attack $=\mathbf{a}$ short thrust by the predator toward a prey individual) stimulated the shrimp's caridoid escape reflex (characteristic backward movement of carideans, brought about by sudden flexure of the abdomen) and ended when the predator caught the prey or the prey individual swam rapidly away from the predator (usually towards cover). As reported elsewhere (Khan et al., 1997), both the predator and the prey were observed entering and moving within all three types of macrophytic cover, but Fundulus, which tended to rest around the edges of the cover or swim in the water column above the cover, entered the cover rarely and then usually when in pursuit of a prey individual that had entered the cover. In general, predators attacked prey when prey were swimming, and predators would pass by closer, inactive prey to attack more distant moving prey. Chases (chase $=\mathrm{a}$ longer episode of Palaemonetes swimming while being pursued by an attacking Fundulus) were uncommon and occurred when the shrimp was swimming above the cover near the water surface. With and without a predator present, $P$. pugio appeared to be a more active swimmer than $P$. vulgaris, spending consistently more time swimming above or outside the cover. In response, attacks upon and chases of prey more often involved $P$. pugio than $P$, vulgaris. From five to forty attacks (not necessarily directed against the same individual) were required for Fundulus to successfully grab an individual shrimp. Capture usually involved Fundulus grabbing the head of the shrimp with its mouth. Typically, 5 minutes elapsed from time of capture to complete consumption of a prey individual.

\section{Macrophytic cover, predation, and survivorship}

Mean numbers of prey survivors in two replicates of 24-hr exposure to predators in the experimental cover conditions, and mean numbers of survivors expected on the basis of assuming no loss to the predator are presented in Table I. The pattern of differences between observed and expected distributions is similar for both species. The number of survivors in the condition of no cover is far less than that expected; "Ambulia" and Ulva are associated with observed numbers of survivors that are 
Table I. Comparison of the observed distribution of survivors (mean of two replicates) with that expected by assuming no loss of individuals due to predation. $\mathrm{O}=$ observed; $\mathrm{E}=$ expected; $* * *=$ significant $(\alpha=.05) ; " n s "=$ not significant $(\alpha=.05)$.

Each prey species exposed alone to predator:

Palaemonetes pugio

\begin{tabular}{lrlll}
\hline Cover condition & \multicolumn{1}{c}{ O } & E & $(\mathrm{O}-\mathrm{E})^{2 / \mathrm{E}}$ & $\mathrm{X}^{2}$ \\
\hline No cover & 9.5 & 20.0 & 5.51 & $9.84^{*}$ \\
"Ambulia" & 13.5 & 20.0 & 2.11 & \\
Ulva & 13.5 & 20.0 & 2.11 & \\
Codium & 18.5 & 20.0 & 0.11 &
\end{tabular}

Palaemonetes vulgaris

\begin{tabular}{lllll}
\hline Cover condition & $\mathrm{O}$ & $\mathrm{E}$ & $(\mathrm{O}-\mathrm{E})^{2} / \mathrm{E}$ & $\mathrm{X}^{2}$ \\
\hline No cover & 12.5 & 20.0 & 2.81 & $4.63 \mathrm{~ns}$ \\
"Ambulia" & 16.0 & 20.0 & 0.80 & \\
Ulva & 15.5 & 20.0 & 1.01 & \\
Codium & 19.5 & 20.0 & 0.01 & \\
\hline
\end{tabular}

Both prey species exposed simultaneously to predator:

Palaemonetes pugio

\begin{tabular}{lrlll}
\hline Cover condition & \multicolumn{1}{c}{$\mathrm{O}$} & $\mathrm{E}$ & $(\mathrm{O}-\mathrm{E})^{2} / \mathrm{E}$ & $\mathrm{X}^{2}$ \\
\hline No cover & 4.5 & 15.0 & 7.3 & $9.86^{*}$ \\
"Ambulia" & 11.5 & 15.0 & 0.82 & \\
Ulva & 10.0 & 15.0 & 1.67 & \\
Codium & 14.5 & 15.0 & 0.02 &
\end{tabular}

Palaemonetes vulgaris

\begin{tabular}{lrlll}
\hline Cover condition & \multicolumn{1}{c}{$\mathrm{O}$} & $\mathrm{E}$ & $(\mathrm{O}-\mathrm{E})^{2 / \mathrm{E}}$ & $\mathrm{X}^{2}$ \\
\hline No cover & 8.5 & 15.0 & 2.82 & $4.46 \mathrm{~ns}$ \\
"Ambulia" & 11.5 & 15.0 & 0.82 & \\
Ulva & 11.5 & 15.0 & 0.82 & \\
Codium & 15.0 & 15.0 & 0.00 & \\
\hline
\end{tabular}

much closer to the numbers expected; and in Codium there is little difference between what is observed and what is expected. This general pattern holds, even when the predator is exposed simultaneously to the two prey species. Chi-square tests comparing the observed and expected distributions (Table I) indicate that for $P$. pugio, whether exposed alone to the predator or simultaneously with $P$. vulgaris, the difference between observed and expected distributions is significant ( $\mathrm{df}=3 ; \alpha=.05)$. For $P$. vulgaris, these differences are not significant.
Predation pressure under the experimental conditions of exposure and cover, as measured by the percentage of the starting prey population missing after 24-hr exposure to the predator, is reported in Table II. Whether exposed alone or together, both prey species are effectively sheltered by Codium, where both species lose $<10 \%$ of the starting population to the predator. However, when exposed alone, the protection afforded $P$. vulgaris by Codium is so great that even the small loss of $P$. pugio is 3.5 times that of $P$. vulgaris. Predation pressure in "Ambulia" and Ulva is similar for both prey species, but for $P$. pugio it is about 1.5 times as much as for $P$. vulgaris. In these moderately protective covers, the presence of the second prey species decreases the predation pressure on $P$. pugio and increases it on $P$ vulgaris. However, neither of the changes associated with the presence of the second prey species is very large. Exposed alone and without cover, predation pressure results in the loss of little more than one-third of the starting population of $P$. vulgaris but removes more than half of the starting population of $P$. pugio. When the two prey species are exposed together without cover to the predator, predatory loss increases for both species ( $6 \%$ for $P$. vulgaris and $18 \%$ for $P$. pugio). Whether exposed without cover alone or in combination with $P$. vulgaris, $P$. pugio bears about one and one-half times the predation pressure of $P$. vulgaris.

Results of the ANOVA performed on survivorship values (as arcsine transformed percentage of starting population) in each condition of experimental cover are reported in Table III. The lack of significant variation contributed by any interaction between and among the three independent sources of variation indicates that the prey ( $P$. pugio and $P$. vulgaris) responded alike to the designed changes in cover, exposure, and species. The lack of significant variation contributed by exposure reveals that the impact of the predator upon a specific prey species was not reduced or enhanced by the presence of an equal number of individuals of the second prey species. The significant variation contributed by the independent sources, cover and species, shows that these variables influenced importantly the number of prey consumed by the predator.

Results of the multiple means analysis (T- 
Table II. Predation pressure under experimental conditions of cover and exposure. Mean number consumed is the difference between the starting number of each prey species (20 in single exposure; 15 in combined exposure) and the mean number (two replicates) surviving after 24 hours exposure to the predator. Predation pressure is the percentage of starting population of prey species consumed.

Each prey species exposed alone to predator

Palaemonetes pugio

\begin{tabular}{lll}
\hline Cover condition & $\begin{array}{l}\text { Mean number } \\
\text { consumed }\end{array}$ & $\begin{array}{l}\text { Predation } \\
\text { pressure }\end{array}$ \\
\hline No cover & 10.5 & 52 \\
"Ambulia" & 6.5 & 32 \\
Ulva & 6.5 & 32 \\
Codium & 1.5 & 7 \\
Palaemonetes vulgaris & & \\
\hline Cover condition & Mean number & Predation \\
& consumed & pressure \\
\hline No cover & 7.5 & 37 \\
"Ambulia" & 4.0 & 20 \\
Ulva & 4.5 & 22 \\
Codium & 0.5 & 2 \\
\hline
\end{tabular}

Both prey species exposed simultaneously to predator

Palaemonetes pugio

\begin{tabular}{lll}
\hline Cover condition & $\begin{array}{l}\text { Mean number } \\
\text { consumed }\end{array}$ & $\begin{array}{l}\text { Predation } \\
\text { pressure }\end{array}$ \\
\hline No cover & 10.5 & 70 \\
"Ambulia" & 3.5 & 23 \\
Ulva & 5.0 & 33 \\
Codium & 0.5 & 3
\end{tabular}

Palaemonetes vulgaris

\begin{tabular}{lll}
\hline Cover condition & $\begin{array}{l}\text { Mean number } \\
\text { consumed }\end{array}$ & $\begin{array}{l}\text { Predation } \\
\text { pressure }\end{array}$ \\
\hline No cover & 6.5 & 43 \\
"Ambulia" & 3.5 & 23 \\
Ulva & 3.5 & $\cdots$ \\
Codium & 0 & 0 \\
\hline
\end{tabular}

method) of the effect of cover are given in Table IV. Predation by Fundulus in the absence of cover caused a loss $>50 \%$ of the experimental population of Palaemonetes prey. This loss of population was reduced significantly by adding cover, allowing at least $70 \%$ of the prey population to survive. The different macrophytic covers, however, were not equally effective in increasing prey survivorship. While Ulva and the plastic "Ambulia" allowed about $30 \%$ loss to the predator, Codium permitted the predator to consume an average of only $2 \%$ of starting population of prey.

The results of means comparison (T-method) of the effect of species are in Table V in which it is shown that overall mean survivorship by $P$. vulgaris was significantly greater than that of $P$. pugio.

\section{Discussion}

1) Is predation pressure the same for both species of grass shrimp?

Because in Table II, the loss of $P$. pugio is about 1.5 times that of $P$. vulgaris, it can be concluded that in the absence of macrophytic cover, predation pressure upon $P$. pugio is greater than that upon $P$. vulgaris. In addition, since the differences between the numbers observed and the numbers expected in Table I are the direct result of predation by Fundulus heteroclitus, it is obvious that predatory loss is greater for $P$. pugio than for $P$. vulgaris. The importance of this difference is emphasized by the fact that for $P$. pugio, loss of individuals is sufficient to cause the distribution of survivors among the cover types to be significantly different from what it would have been if there had been no predator. For $P$. vulgaris, the numbers taken by the predator are insufficient to cause the distribution among the cover types to deviate significantly from that expected without predation. The significance of species as an independent source of variation (Table III) and the subsequent means analysis (Table V) reiterate the conclusion that predation on $P$. pugio is greater than that on $P$. vulgaris. Furthermore the failure of the cover-by-species interaction to be significant (Table III) indicates that although altering the cover type does significantly change the number of individuals lost to the predator, it does not change the relationship of predatory loss between the two prey species, i.e. more $P$. pugio are eaten regardless of the cover type. The behavioral observations of the present study may pro- 
vide some insight as to why losses of $P$. pugio are greater than those of $P$. vulgaris. With and without a predator present, $P$. pugio appeared to be a more active swimmer than $P$. vulgaris, spending consistently more time swimming above the substrate or outside the cover. In response, chases between predator and prey more often involved $P$. pugio than $P$. vulgaris.

2) Does macrophytic cover reduce the amount of predatory loss for one or the other prey species of grass shrimp?

Other investigators (Heck and Thomas, 1981; Rozas and Odum, 1988) have suggested that macrophytic cover provides shelter for Palaemonetes in the presence of Fundulus. Our results (Table I) support this suggestion in that for both prey species, predator induced losses cause the difference in distribution of survivors among the cover types to be different from that expected on the basis of assuming no loss to predators. For both prey species in both exposure conditions, the differences between the observed and expected numbers are greater for the "no cover" condition. However, the difference between the observed distribution (after predatory loss) and the expected distribution of survivors (assuming no predation) is significant only for $P$. pugio. Thus, our results not only point out increased Palaemonetes survivorship associated with macrophytic vegetation, they also indicate that macrophytic cover shelters $P$. vulgaris better than it shelters $P$. pugio.

The ANOVA (Table III), in its indication that cover is a significant source of variation restates the conclusion that cover significantly affects survivorship of $P$. pugio and $P$. vulgaris. The means analysis of the effect of cover (Table IV) emphasizes the importance of macrophytes in reducing loss of shrimp to the predatory killifish by showing that without cover, more than half of the starting population of Palaemonetes is consumed by Fundulus, but in cover provided by the macrophyte, Codium, survivorship (percent of starting population) more than doubles. Heck and Thomas (1981) feel that reduction in predatory loss of grass shrimp in dense macrophytes is the direct result of serious restriction of the fish's movement. Although this may be the
Table III. Three Factor Analysis of Variance of arcsine transformed survivorship (expressed as percentage of starting population) of prey species $\left(P_{\times}\right.$pugio and $P \times$ vulgaris $)$ under different condition of cover and after 24-hour exposure to the predator Fundulus heteroclitus. The independent sources of variation were type of "cover" (none, "Ambulia", Ulva, Codium), "exposure" (prey species exposed to predator alone or with both prey species present) and "species" (P. pugio and $P$, vulgaris).

\begin{tabular}{lrrrl}
\hline Source & df & \multicolumn{1}{c}{ MS } & F & $\begin{array}{l}\text { Decision } \\
(\alpha=.05)\end{array}$ \\
\hline Total & 31 & & & \\
Cover & 3 & 2030.70 & 74.62 & significant \\
Exposure & 1 & 1.37 & 0.05 & not significant \\
Cover $\times$ Exposure & 3 & 79.29 & 2.91 & not significant \\
Species & 1 & 394.03 & 14.48 & significant \\
Cover × Species & 3 & 34.83 & 1.28 & not significant \\
Exposure $\times$ Species & 1 & 10.75 & 0.40 & not significant \\
Cover × Exposure $\times$ & & & & \\
$\quad$ Species & 3 & 24.23 & 0.89 & not significant \\
Replicate = Error & 16 & 27.21 & & \\
\hline
\end{tabular}

case, observations of behavior in the present study reveal that predators are far more likely to capture prey when they are swimming, and prey typically do not swim but rest or walk slowly among the branches or thalli of the cover. Several investigators have shown that in the presence of predators, movement of invertebrate prey species decreases and prey movement is likely to bring about a predatory attack. Stein and Magnuson (1976) documented such behavior of crayfish in the presence of potentially predatory fish. Heck and Thomas (1981) reported that killifish attacked grass shrimp only when the latter are actively swimming near the water surface. Thus, the behavioral observations of this study and the description associating prey movement with intensity of predation suggest that the protection afforded shrimp by cover is the indirect result of shrimp tending to remain more stationary when in cover.

Khan et al. (1997) found that in the absence of predators and when given the opportunity to choose, $P$. pugio and $P$. vulgaris rest least often on bare substrate, most often in Codium, and in intermediate numbers in "Ambulia" and Ulva. The similarity in distribution of individuals seen in this and the present study in the presence and absence of predators suggests that Palaemonetes may settle in cover in response to cues that are unrelated to predation 
pressure. However, an alternative explanation for the choice of covered resting place in the absence of predators might be that these field-caught but laboratory-tested prey individuals are expressing residual conditioning acquired in the field where predators are common. This alternative explanation is consistent with the reports by Coen et al. (1981), Heck and Thomas (1981), and Primavera (1997) in which it is held that shrimp seek "covered" habitat as refuge from predation. Resolution of this issue awaits further investigation.

3) If macrophytic cover reduces loss to predators, are all kinds of macrophytic cover equally effective in reducing the loss?

The obvious conclusion drawn from Table IV is that different kinds of cover are not alike in the amount of protection they provide. While predatory loss in Codium isabout $2 \%$ of the starting population, the living macrophyte, Ulva, and the plastic plant resembling Ambulia are similar in providing significantly less protection (about $22 \%$ loss of individuals). The similarity in shrimp survivorship in Ulva and in the plastic plant ("Ambulia") strongly suggests that the protective role of cover is simply that of providing increased structural complexity within which the shrimp and their activity is concealed from the predator. Main (1987) concluded that a predator might view macrophytic cover as a complex opaque environment that stands as a visual barrier between predator and prey. Codium, a coarsely branched macrophyte, certainly provides a greater physical complexity and heterogeneity than "Ambulia" with its regular arrangement of "stems" and "leaves." Ulva, with its flopped-over, closely appressed thallus and lower vertical depth may provide even less structural complexity than "Ambulia," however, compared to "Ambulia" the effect of this difference on shrimp survivorship is not significant.

4) Does the presence of the second prey species of grass shrimp enhance or lessen the predatory loss of the first prey species?

Thorp (1976) has suggested that $P$, vulgaris behaviorally dominates $P$. pugio, excluding it from
Table IV. Means analysis of the effect of cover on prey survivorship. Values in the table are mean arcsine transformed survivorship values for prey (Palaemonetes) under various conditions of cover after 24-hour exposure to the predator Fundulus heteroclitus. Means followed by the same lower case letter are not significantly different ( $T$-method; $\alpha=.05$ ). Numbers in parentheses after the tabulated mean are back-transformed mean percent values.

\begin{tabular}{ll}
\hline Cover & Mean survivorship \\
\hline None & 44.15 a (48.5) \\
"Ambulia" & $59.77 \mathrm{~b}(74.6)$ \\
Ulva & $57.71 \mathrm{~b}(71.5)$ \\
Codium & $82.16 \mathrm{c}(98.1)$ \\
\hline
\end{tabular}

Table V. Means analysis of the effect of species on prey survivorship. Values in the table are mean arcsine transformed survivorship values for prey (Palaemonetes pugio and Palaemonetes vulgaris) under various conditions of cover after 24-hour exposure to the predator Fundulus heteroclitus. Means followed by the same lower case letter are not significantly different (T-method; $\alpha=.05$ ). Numbers in parentheses after the tabulated mean are back-transformed mean percent values.

\begin{tabular}{ll}
\hline Species & Mean survivorship \\
\hline$P$. pugio & $57.00 \mathrm{a}(70.3)$ \\
$P$. vulgaris & $64.90 \mathrm{~b}(82.0)$ \\
\hline
\end{tabular}

sheltering habitat thereby causing its greater loss to predators. Similarly, the data in Table II suggest that exposure of $P$. pugio to Fundulus heteroclitus in the presence of $P$. vulgaris causes greater loss to the predator (especially without cover). If, in the present study, $P$. vulgaris were indeed excluding $P$. pugio from sheltered habitat, then survival of $P$. pugio in the presence of $P$. vulgaris and $F$. heteroclitus should be significantly lower than in the presence of $F$. heteroclitus alone. At the same time, survival of $P$. vulgaris alone should be no different from its survival in the presence of both the predator and the alternative prey, $P$. pugio. However, the ANOVA (Table III) fails to assign a significant amount of variation to the exposureby-species interaction. This failure indicates that survival of both species was affected similarly by the presence of the other species. Furthermore, variation contributed by exposure as an independent source of variation was not significantly greater than that associated with chance. Thus, the impact of the predator in the presence of a second prey 
was not significantly different from the predator's impact with only one prey available. The contradiction between this conclusion of the present work and Thorp's suggestion probably results from Thorp's failure to consider the difference in swimming activity of $P$. pugio and $P$. vulgaris.

\section{Acknowledgements}

We would like to thank Dr. Jaren Horsley for allowing us to conduct this research using the facilities of the Smithsonian Institution's National Zoological Park. We are grateful to $\mathbf{M}$. Lucas, M. Holland, A. Peters, A. Keech, and E. Smith for sharing their enthusiasm.

\section{References}

Anderson G. 1985. Species profiles: life histories and environmental requirements of coastal fishes and invertebrates (Gulf of Mexico) grass shrimp. U.S. Fish. Wild. Serv. Biol. Rep. 82(11.35).

Coen LD, Heck KL, Abele LG. 1981. Experiments on competition and predation among shrimps of seagrass meadows. Ecology 62: 1484-1493.

Everett RA, Ruiz GM. 1993. Coarse woody debris as a refuge from predation in aquatic communities: an experimental test. Oecologia 93: 475-486.

Heck K, Thomas T. 1981. Experiments on predator-prey interactions in vegetated aquatic habitats. $J$. Exp. Mar. Biol. Ecol. 53: 125-134.

Khan RN, Knowlton RE, Merchant HC. 1995. Distribution to two sympatric species of grass shrimp Palaemonetes pugio and Palaemonetes vulgaris in relation to homogeneous and heterogeneous aquarium substrates. $J$. Elisha Mitchell Sci. Soc. 111: 83-95.

Khan RN, Merchant HC, Knowlton RE. 1997. Effects of macrophytic cover on the distribution of grass shrimps, Palaemonetes pugio and $P$. vulgaris. Invert. Biol. 116: 243-247.
Kneib RT. 1988. Testing for indirect effects of predation in an intertidal soft-bottom community. Ecology 69: 17951805.

Knowlton RE, Khan RN, Arguin PM, Aldaghlas TA, Sivapathasundram R. 1994. Factors determining distribution and abundance of Delmarva grass shrimp (Palaemonetes spp). Virginia $J_{*}$ Sci. 45: 231-247.

Main KL. 1987. Predator avoidance in seagrass meadows: prey behavior, microhabitat selection, and cryptic coloration. Ecology 56: 1388-1897.

Orth RJ, Heck KL jr, Montfrans J. von. 1984. Faunal communities in seagrass beds: a review of the influence of plant structure and prey characteristics on predatorprey relationships. Estuaries 7: 339-350.

Overstreet RM, Heard RM. 1982. Food contents of six common fishes from Mǐssissippi Sound. Gulf Res. Rep. 7. 137-149.

Primavera JH. 1997. Fish predation on mangrove-associated penaeids: the role of structures and substrates. $J$. Exp. Mar. Biol. Ecol. 215: 205-216.

Rozas LP, Odum WE. 1988. Occupation of submerged aquatic vegetation by fishes: testing the roles of food and refuge. Oecologia 77: 101-106.

Ruiz GM, Hines AH, Posey MH. 1993. Shallow water as a refuge habitat for fish and crustaceans in non-vegetated estuaries: an example from Chesapeake Bay. Mar. Ecol. Prog. Ser. 99: 1-16.

Sokal RR, Rohlf FJ. 1995. Biometry: the Principles and Practice of Statistics in Bíological Research. New York: W.H. Freeman.

Stein RA, Magnuson JJ. 1976. Behavioral response of crayfish to a fish predator. Ecology 57: 751-761.

Tayasu I, Shigesada N, Mukai H, Caswell H. 1996. Predatormediated coexistence of epiphytic grass shrimps that compete for refuges. Ecol. Mod. 84; 1-10.

Thorp JH. 1976. Interference competition as a mechanism of coexistence between two sympatric species of the grass shrimp Palaemonetes (Decapoda: Palaemonidae). J. Exp. Mar. Biol. Ecol. 25: 19-35.

Williams AB. 1984. Shrimps, Lobsters, and Crabs of the Atlantic Coast of the Eastern United States, Maine to Florida. Washington, DC $x$ Smithsonian Institution Press.

Receivved: 12 September $\mathbf{2 0 0 0}$ 


\section{Appendix}

Data used in the analysis of survivorship of Palaemonetes pugio and $P$, vulgaris in the presence of the predator Fundulus heteroclitus under various conditions of macrophytic cover.

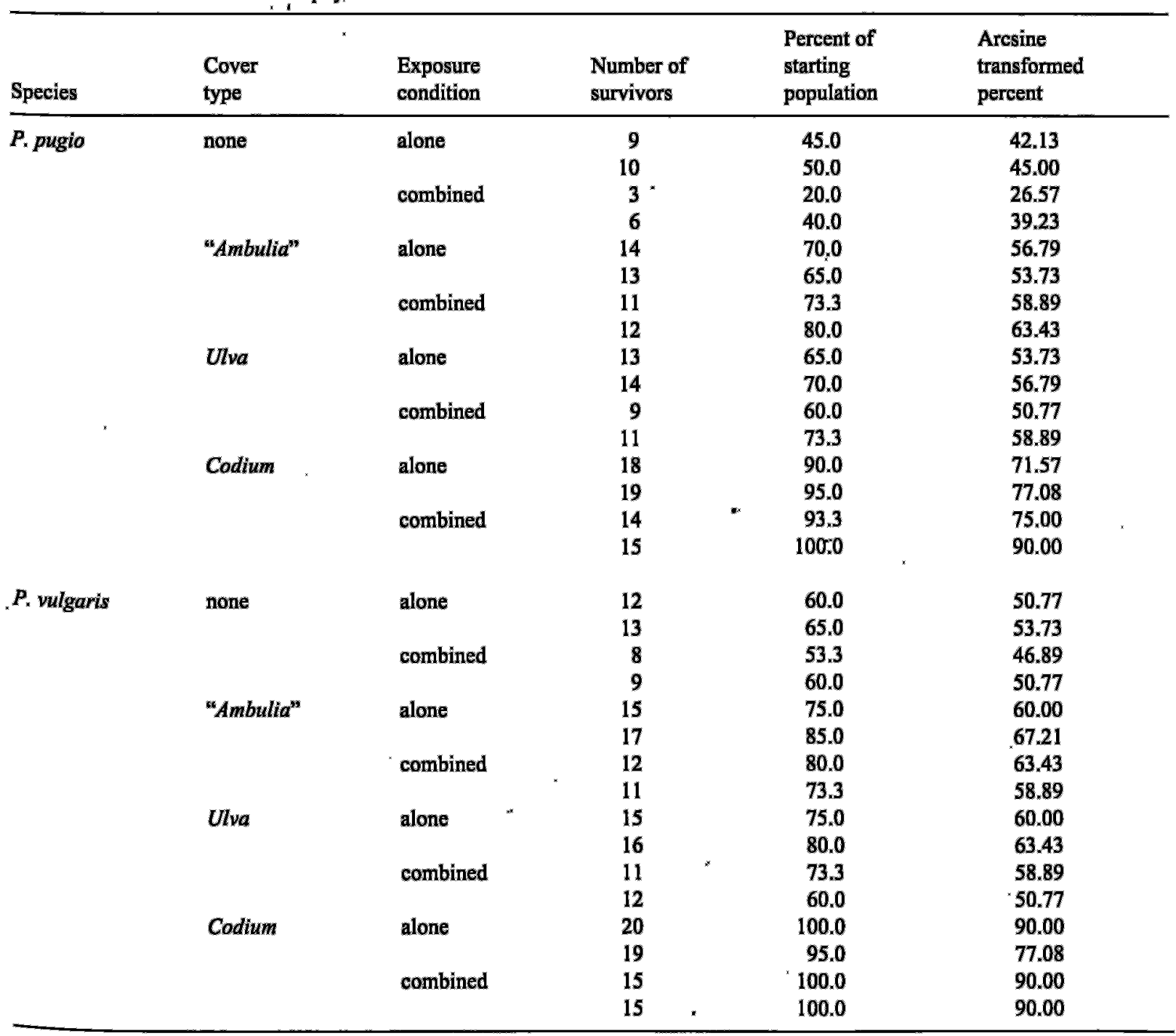

